\title{
Provimento de Cargos em Comissão nas Secretarias de Desenvolvimento Regional do Estado de Santa Catarina
}

\author{
Provision of Committee Positions at Regional Development Departments
in the State of Santa Catarina
}

\author{
Marcio Cassol Carvalho \\ Especialista em Estudos Estratégicos da Administração Pública, Fundação Escola de Governo ENA/UDESC - Florianópolis - SC, \\ Brasil.E-mail: marcio1996@hotmail.com
}

\section{Ademar Dutra}

Professor do Programa Pós-Graduação em Administração, Universidade do Sul de Santa Catarina - Florianópolis - SC, Brasil.

E-mail: ademar.unisul@gmail.com

Cristina Martins

Mestranda do Programa Pós-Graduação em Administração, Universidade do Sul de Santa Catarina - Florianópolis - SC, Brasil. E-mail: crismartins2611@gmail.com

\section{Marcos Baptista Lopez Dalmau}

Professor do Programa de Pós-Graduação em Administração, Universidade Federal de Santa Catarina - Florianópolis - SC, Brasil. E-mail: dalmau@cse.ufsc.br

\section{Resumo}

O objetivo do presente artigo visa investigar e avaliar a influência do nível de escolaridade e da filiação político-partidária no provimento de cargos em comissão das atividades finalísticas das Secretarias de Desenvolvimento Regional do Estado de Santa Catarina. A pesquisa é de caráter descritivo, na forma de um estudo multicaso, com a abordagem quali-quantitativa, envolvendo dados primários $e$ secundários. Os resultados do estudo apontam que: (i) $83 \%$ dos gerentes pesquisados possuem filiação partidária, demonstrando que esta variável tem influência na ocupação dos cargos comissionados; (ii) $29 \%$ dos gerentes não possuem escolaridade de nível superior; (iii) $40 \%$ dos gestores não possuem escolaridade compatível com a exigida para o exercício do cargo. Assim, conclui-se que a filiação políticopartidária é o principal requisito para o provimento de cargos em comissão, enquanto o nível de escolaridade é aplicado de forma secundária.

Palavras-chave: Cargos em Comissão. Desenvolvimento Regional. Nível de escolaridade. Filiação Político-Partidária.

\section{Abstract}

The aim of this paper is to investigate and evaluating the influence of educational level and political party affiliation in filling committee positions in the final activities of the Regional Development Departments in the State of Santa Catarina. The research is of descriptive character, in the form of a multicase study, with quali-quantitative approach, involving primary and secondary data. The results of the study point that: (i) $83 \%$ of the searched managers have political party affiliation, demonstrating that this variable has influence in the occupation of the commissioned positions; (II) $29 \%$ of the managers do not possess high educational level; (III) $40 \%$ of the managers do not possess compatible educational level with the demanded one for the position exercise. Thus, we conclude that the political party affiliation is the main requirement for the provision of committee positions, while the educational level is applied as secondary form.

Key words: Committee positions. Regional development. Educational level. Political party affiliation. 


\section{INTRODUÇÃo}

No âmbito da união, dos estados e dos municípios, os cargos comissionados representam a estrutura de gestão de cada órgão/entidade pública, sendo definidos por Lei e destinando-se às atribuições de direção, chefia e assessoramento, conforme estabelece a Constituição da República Federativa do Brasil de 1988 - CRFB/88 (BRASIL, 1988). Esses cargos, na administração pública brasileira, são providos essencialmente por indicação (CÂMARA, 2009), pois têm como característica a livre nomeação e exoneração, sem necessitar para a sua investidura a aprovação prévia em concurso público. Como consequências negativas dessa regra, tem-se a prática do nepotismo, como também a ausência de qualificação técnica em muitas nomeações.

Apesar da mudança substancial quanto ao nepotismo, proibido para cargos comissionados envolvendo parentes de até terceiro grau de agentes públicos dos Poderes Executivo, Legislativo e Judiciário, situação até então corriqueira na administração pública brasileira (BRASIL, 2008), a disputa por cargos públicos é contínua e intensa a cada ciclo de governo. Os candidatos aos cargos majoritários (presidente, governador, prefeito), comumente são eleitos por meio de uma coalizão de partidos que luta por espaços dentro da máquina estatal, no sentido de acomodar seus afiliados políticos $e$ influenciar as decisões governamentais.

Nesse contexto, há uma dicotomia entre a busca pela governabilidade, representada por uma base parlamentar que assegure sustentação política no legislativo com a formulação e a implementação de políticas públicas. Se, por um lado, a escolha dos gestores públicos atender aos anseios dos partidos que formam a base governista; por outro, as escolhas, motivadas por critérios não técnicos, podem acarretar prejuízos na gestão pública e por consequência no atendimento das necessidades da população.

No governo do Estado de Santa Catarina isto não é diferente. O governo eleito no período de 2011 a 2014 é formado por uma coligação de nove partidos, todos em busca da ocupação dos cargos comissionados, em especial das Secretarias de Desenvolvimento Regional (SDRs), órgãos distribuídos por microrregiões no âmbito do território catarinense.
As SDRs foram criadas em 2003, por meio de uma reforma administrativa, tendo como motivação principal a descentralização do governo, na tentativa de minorar as desigualdades regionais do Estado pela ausência de projetos de desenvolvimento regionalizados, bem como combater a "litoralização", que consiste no deslocamento da população residente no interior para as cidades localizadas no litoral. Além disso, a intenção do Estado era que as decisões governamentais fossem tomadas mais próximas dos problemas públicos e com a participação dos cidadãos na definição das políticas públicas de sua região.

Diante do exposto, surge a questão-problema que permeia o estudo: qual a influência do nível de escolaridade e da filiação partidária para o provimento dos cargos em comissão das áreas finalísticas das SDRs?

Para responder tal problemática, tem-se como objetivo deste artigo investigar a influência do nível de escolaridade e da filiação político-partidária no provimento dos cargos em comissão das atividades finalísticas nas SDRs no Estado de Santa Catarina.

Estudos similares têm sido desenvolvidos por autores como Olivieri (2007); Santos (2009); Câmara (2009); Bernardi e Campos (2010); e Côrrea (2010). No entanto, ressalta-se que apesar dos autores referenciados abordarem o tema cargos comissionados, nenhum deles investiga a influência do nível de escolaridade e da filiação político-partidária no provimento desses cargos.

Como justificativa do presente estudo, destaca-se que a qualidade da gestão está diretamente relacionada ao perfil do ocupante do cargo comissionado, que se negligenciado compromete o atendimento das demandas da sociedade, visto que as políticas públicas podem não ser formuladas e/ou implementadas de forma adequada.

Quanto à organização, esta pesquisa é composta por quatro seções: (i) Referencial Teórico; (ii) Metodologia; (iii) Análise dos Resultados, e, por fim, (iv) Considerações Finais do estudo.

\section{Referencial Teórico}

Os eixos que norteiam o referencial teórico envolvem os temas dimensão política e dimensão técnica no provimento de cargos em comissão, e a caracterização das SDRs. 


\subsection{Dimensão Política e a Dimensão Técnica no Provimento de Cargos em Comissão}

A organização da burocracia no Brasil foi afetada pela não utilização do sistema de mérito para a contratação de servidores públicos para cargos temporários, como também pela burla do concurso público para o ingresso de servidores em caráter permanente. Além disso, após o estabelecimento de regras mais rígidas para o ingresso no serviço público, proliferou-se o uso das formas de livre provimento para o exercício de cargos de confiança. (SANTOS, 2009)

Isso pode ser explicado pelas origens históricas na formação das instituições jurídicas brasileiras, as quais sofreram uma contraditória confluência entre a herança colonial ibérica burocrática-patrimonialista e a tradição liberal individualista, que se caracterizaram na união de práticas ausentes da democracia e participação juntamente ao exclusivo interesse das elites hegemônicas locais, detentoras do poder, da propriedade privada e dos meios de produção da riqueza. (WOLKMER, 2006, p. 94)

Desse modo, prevalece, ainda, no Brasil uma visão patrimonialista, personalista sobre os cargos públicos, como se eles fossem propriedade daquele que tem o poder de nomear, à revelia do interesse público $e$ à mercê do interesse pessoal do agente político. (WIARDA, 1983; AYLLÓN; GUERRERO, 2005)

A política de escolha das pessoas que serão investidas em cargos de confiança é realizada normalmente pelo grupo político que foi eleito para um determinado mandato. Segundo Bernardi e Campos (2010), geralmente há relação de confiança entre o nomeado e a autoridade que nomeou.

Entretanto, a escolha dos ocupantes dos cargos de confiança que compõem a máquina governamental influi diretamente na governabilidade e na governança. A governabilidade é afetada, pois o governo depende de uma base parlamentar forte para aprovar os projetos de seu interesse e acaba utilizando os cargos de confiança como moeda de troca pelo apoio dos parlamentares/partidos. A governança, por outro lado, pode ser influenciada pela (in) capacidade do governo em formular e implementar políticas públicas, devido ao grau técnico ou não de seus gestores. (OLIVIERI, 2007; CÔRREA, 2010)
Em suma, adverte Santos (2010, p. 11),

[...] a eficiência depende, em parte, de um corpo profissional e contínuo, imune às interferências $e$ às influências políticas diretas.

Nesse sentido, a falta de definição de quais os cargos de confiança que necessitam de pessoas capacitadas tecnicamente para seu exercício, e, por outro lado, quais cargos são eminentemente políticos, acaba por flexibilizar em demasia as nomeações, impedindo de certa forma a definição de um perfil profissional e a construção de um sistema de mérito, que faça a ligação entre os melhores profissionais e os postos de gestão na administração pública. (ALENCAR, 2006)

Diante desse quadro, necessita-se, além de competências adaptadas à realidade, definir parâmetros para a escolha dos ocupantes de cargos de confiança, como traços de caráter, atitudes ou valores, habilidades e capacidades cognitivas ou de conduta, assim como acontece com os cargos de provimento efetivo, respeitando somente o atributo da livre nomeação $e$ exoneração $e$, consequentemente, diminuindo a discricionariedade da autoridade com poder de nomear e fortalecendo a capacidade de direção nas organizações públicas. (LONGO, 2003; SEGUNDO, 2010)

Desse modo, a conciliação entre as competências técnicas e políticas contribuem para a formação de um profissional híbrido, que ficará responsável tanto por uma gestão eficiente como compromissado com os objetivos políticos da agenda governamental. (OLIVIERI, 2007)

\subsection{As Secretarias de Desenvolvimento Regional (SDRs)}

Em 2003, pela Lei Complementar n. 243, de 30 de janeiro de 2003 (SANTA CATARINA, 2003), deu-se início a política de descentralização administrativa no Estado de Santa Catarina, por meio da criação de 29 SDRs distribuídas pelo território catarinense, abrangendo cada uma delas um conjunto de municípios. Dutra et al. (2008) assinala que o objetivo do novo modelo de gestão visava a desburocratização e a descentralização, a melhoria dos processos e a correta gestão da informação, a transformação do Estado em referência em desenvolvimento sustentável nas dimensões ambiental, econômica, social e tecnológica, bem 
como a promoção e a redução das desigualdades entre cidadãos e regiões, elevando a qualidade de vida de sua população.

Com a criação das SDRs, boa parte das funções até então realizadas pelas Secretarias Setoriais (Centrais), foram repassadas às novas estruturas, com a finalidade de impulsionar o desenvolvimento de suas regiões (ABRUCIO E FILIPPIM, 2008). Desse modo, as Secretarias Setoriais (Fazenda, Planejamento, Administração, Saúde, Educação etc.), foram imbuídas do papel de normatizar, formular e controlar as políticas públicas e coube às regionais o papel de coordenar e executar as políticas públicas. (SANTA CATARINA, 2011)

Atualmente, pelas Leis que se sucederam (Lei Complementar n. 285/05, n. 381/07 e n. 534/11, SANTA CATARINA, 2005, 2007, 2011), o Estado possui 36 SDRs dispostas em microrregiões. O Quadro 1 ilustra essa distribuição e a estrutura organizacional subdivida em quatro grupos "A", "B", "C" e "D", representando o porte de cada SDR.

\begin{tabular}{|c|c|c|c|c|}
\hline TIPO & $\begin{array}{l}\text { DistRIBUiÇÃo SDRs } \\
\text { (MicRORREGIÕES) }\end{array}$ & $\begin{array}{l}\text { NúME- } \\
\text { RO DE } \\
\text { SDRs }\end{array}$ & $\begin{array}{l}\text { TOTAL DE CARGOS } \\
\text { COMISSIONADOS }\end{array}$ & $\begin{array}{l}\text { CARGOS COMISSIO- DeNOMINAÇão dOS CARGOS COMISSIONAdOS NAS ÁREAS } \\
\text { NADOS POR SDR } \\
\text { FINALíSTICAS }\end{array}$ \\
\hline
\end{tabular}

\begin{tabular}{|c|c|c|c|c|c|}
\hline A & $\begin{array}{l}\text { Grande Florianópolis } \\
\text { e Joinville }\end{array}$ & 2 & 40 & 20 & $\begin{array}{l}\text { Consultor Jurídico; Assessor de Comunicação; } \\
\text { Assistente Técnico; Assistente do Secretário; Diretor } \\
\text { Geral; Gerência de Planejamento e Avaliação; } \\
\text { Gerência de Administração, Finanças e Contabilidade; } \\
\text { Gerência de Recursos Humanos; Gerência de } \\
\text { Apoio Operacional; Gerência de Convênios } \\
\text { Contratos e Licitações; Gerências de Tecnologia } \\
\text { da Informação; Gerência de Educação; Gerência } \\
\text { de Assistência Social Trabalho e Habilitação; } \\
\text { Gerência de Saúde; Gerência do Desenvolvimento } \\
\text { Econômico Sustentável e Agricultura; Gerência de } \\
\text { Turismo, Cultura e Esporte; Gerência de Projetos } \\
\text { Especiais (2); Gerência de Infraestrutura. }\end{array}$ \\
\hline
\end{tabular}

\begin{tabular}{|c|c|c|c|c|c|}
\hline B & $\begin{array}{l}\text { Blumenau, Chapecó, } \\
\text { Criciúma, Itajaí, Lages. }\end{array}$ & 5 & 85 & 17 & $\begin{array}{l}\text { Consultor Jurídico; Assessor de Comunicação; } \\
\text { Assistente Técnico; Diretor Geral; Gerência de } \\
\text { Planejamento e Avaliação; Gerência de Administração, } \\
\text { Finanças e Contabilidade; Gerência de Recursos } \\
\text { Humanos; Gerência de Apoio Operacional; Gerências } \\
\text { de Tecnologia da Informação; Gerência de Educação; } \\
\text { Gerência de Assistência Social Trabalho e Habilitação; } \\
\text { Gerência de Saúde; Gerência do Desenvolvimento } \\
\text { Econômico Sustentável e Agricultura; Gerência } \\
\text { de Turismo, Cultura e Esporte; Gerência de } \\
\text { Projetos Especiais; Gerência de Infraestrutura. }\end{array}$ \\
\hline C & $\begin{array}{l}\text { Araranguá, Brusque, } \\
\text { Caçador, Campos } \\
\text { Novos, Canoinhas, } \\
\text { Concórdia, } \\
\text { Curitibanos, Jaraguá } \\
\text { do Sul, Joaçaba, } \\
\text { Laguna, Mafra, Rio } \\
\text { do Sul, São Miguel } \\
\text { d'Oeste, Tubarão, } \\
\text { Videira e Xanxerê }\end{array}$ & 16 & 176 & 11 & $\begin{array}{l}\text { Consultor Jurídico; Assessor de Comunicação; } \\
\text { Diretor Geral; Gerência de Planejamento e } \\
\text { Avaliação; Gerência de Administração, Finanças e } \\
\text { Contabilidade; Gerência de Educação; Gerência de } \\
\text { Assistência Social Trabalho e Habilitação; Gerência } \\
\text { de Saúde; Gerência do Desenvolvimento Econômico } \\
\text { Sustentável e Agricultura; Gerência de Turismo, } \\
\text { Cultura e Esporte; Gerência de Infraestrutura. }\end{array}$ \\
\hline D & $\begin{array}{l}\text { Braço do Norte, } \\
\text { Dionísio Cerqueira, } \\
\text { Ibirama, Itapiranga, } \\
\text { Ituporanga, Maravilha, } \\
\text { Palmitos, Quilombo, } \\
\text { São Joaquim, São } \\
\text { Lourenço do Oeste, } \\
\text { Seara, Taió e Timbó }\end{array}$ & 13 & 118 & 9 & $\begin{array}{l}\text { Consultor Jurídico; Assessor de Comunicação; } \\
\text { Diretor Geral; Gerência de Administração, Finanças } \\
\text { e Contabilidade; Gerência de Educação; Gerência de } \\
\text { Assistência Social Trabalho e Habilitação; Gerência } \\
\text { de Saúde; Gerência do Desenvolvimento Econômico } \\
\text { Sustentável e Agricultura; Gerência de Infraestrutura. }\end{array}$ \\
\hline \multicolumn{2}{|c|}{ TOTAL } & 36 & 419 & 57 & \\
\hline
\end{tabular}

Quadro 1: Cargos Comissionados nas SDRs

Fonte: Adaptado de Anexo VIII, Lei Complementar n. 381/07 (SANTA CATARINA, 2007) 
Cabe ressaltar que apenas a SDR de São Joaquim possui um cargo em comissão a mais do que as outras do grupo "D" (Gerente de Turismo, Cultura e Esporte). No Quadro 1 não são computados os cargos de Secretário e Secretário Adjunto das SDRs, por caracterizarem-se como agentes políticos.

\subsubsection{Requisitos e Restrições para a Investidura em Cargos em Comissão}

A Reforma Administrativa em vigor foi aprovada pela Lei Complementar n. 381/07 (SANTA CATARINA, 2007), cuja última alteração ocorreu no exercício de 2011, em virtude da posse do novo Governador do Estado, Lei Complementar n. 534/11(SANTA CATARINA, 2011). O artigo 160 da Lei Complementar n. 381/07 (SANTA CATARINA, 2007) dispõe sobre a estruturação dos cargos em comissão e funções de confiança dos órgãos e entidades da Administração Direta, Autárquica e Fundacional do Poder Executivo no Estado. Cabe ressaltar que o Estado cumpre o dispositivo constitucional (BRASIL, 1988, art. 37, V) que exige percentual mínimo de cargos de comissão que serão ocupados por servidores de carreira.

Dessa forma, a Lei Complementar n. 381/07 (SANTA CATARINA, 2007) estabelece em seu artigo 163 um perfil profissional genérico para os ocupantes de cargos em comissão e funções de confiança, e, também exigências pontuais para alguns cargos em comissão, como, por exemplo, Consultor Jurídico (graduação em direito), Assessor de Comunicação (graduação em jornalismo ou comunicação social) e Gerente de Infraestrutura (estar inscrito no CREA/CONFEA). Quanto à idade mínima para a investidura nos cargos em tela, respeita-se a regra atribuída aos cargos de provimento efetivo, qual seja, no mínimo 18 anos.

Por fim, registre-se que todos os cargos objeto desta pesquisa são do tipo (Direção de Gerenciamento Superior (DGS) ou Funções Técnicas Gerenciais (FTG), dependendo da filiação do ocupante com o serviço público.

No que tange às restrições para ser nomeado para cargo em comissão, o ordenamento jurídico estabelece algumas limitações que impedem determinadas pessoas de ocupar tais cargos. Essas restrições são comumente denominadas de proibição ao nepotismo e Lei da Ficha Limpa.
Posteriormente, no Estado de Santa Catarina, por meio do Decreto n. 1.836, de 06 de novembro de 2008 (SANTA CATARINA, 2008), foi regulamentado o tema em questão nos seguintes termos:

VEDA-SE A NOMEAÇÃo de CONJU-
GE, COMPANHEIRO (A) OU PAREN-
TE, ATÉ O TERCEIRO GRAU de:

Governador e Vice-Governador Cargo em comissão, de confiança do Estado. ou de função gratificada na administração pública estadual direta e indireta.

Secretários de Estado, Secretários Cargo em comissão, de confiança Executivos, Secretário Especial, ou de função gratificada no Procurador Geral do Estado. Poder Executivo estadual, no âmbito da administração direta, autárquica e fundacional.

Para estrutura do órgão em que Caso o cônjuge, companheiro for o superior hierárquico. (a) ou parente for servidor Diretores Gerais ou substitutos público efetivo. legais dos titulares dos órgãos ou entidades.

Diretores e Gerentes. Cargo em comissão, de confiança ou de função gratificada no Poder Executivo estadual, no âmbito do órgão em que exercem o cargo.

Dirigentes máximos da Cargoem comissão, de confiança administração indireta, no âmbito ou de função gratificada.

da mesma pessoa jurídica.

Quadro 2: Vedações de nepotismo aplicadas pela legislação Fonte: Adaptado de Decreto n. 1.836, de 6 de novembro de 2008 (SANTA CATARINA, 2008)

Além da proibição do nepotismo, em 2010 foi editada no âmbito do Estado de Santa Catarina a Lei n. 15.381, de 17 de dezembro de 2010 (SANTA CATARINA, 2010), que disciplina a nomeação para cargos em comissão no âmbito dos órgãos dos Poderes Executivo, Legislativo, Judiciário e do Tribunal de Contas do Estado. Esta norma trouxe para a legislação catarinense dispositivos presentes na Lei da Ficha Limpa (Lei Complementar Federal n. 135, de 4 de junho de 2010). No entanto, na Lei Federal que tem por objetivo proteger a probidade administrativa e a moralidade no exercício do mandato, são previstos casos de ilegibilidade para cargos eletivos como Presidente, Governador, Prefeito etc. Já na legislação catarinense, esses casos são considerados fatores impeditivos para a nomeação de cargos comissionados, existindo uma gama de impedimentos para o exercício 
de cargo comissionado em Santa Catarina, além dos requisitos como escolaridade, o que retira dos quadros públicos pessoas de má índole e aquelas que já tiveram passagens em órgãos governamentais $e$ produziram resultados negativos para a sociedade.

\subsubsection{A Relação Política Partidária na Investidura em Cargos em Comissão}

Além dos requisitos estabelecidos pela Lei Complementar n. 381/07 (SANTA CATARINA, 2010), a escolha dos ocupantes dos cargos de confiança nas
SDRs tem se baseado também por questões político-partidárias. (ABRUCIO; FILIPPIM, 2008). Ao analisar o mandato governamental (2007-2010), os autores afirmam que os meios de comunicação da maioria dos municípios sede das SDRs discorria sobre uma intensa disputa política partidária pelos cargos de Secretário, Diretor e Gerente. Tal constatação se repete no início do atual mandato governamental (2011-2014), conforme, levantamento efetuado junto ao sítio de busca "Google" no dia 18 de outubro de 2011, utilizando as expressões "secretaria desenvolvimento regional", "cargos" e "2011", em que se destacam as seguintes notícias:

\begin{tabular}{|c|c|c|}
\hline DAta & ORIGEM & Notícias \\
\hline $20 / 01 / 11$ & Estado & $\begin{array}{l}\text { A diretriz escolhida pelo governo não segue a "geografia das urnas", reivindicada pelos aliados. Na nova } \\
\text { distribuição de cargos por partido: o PMDB tem } 35 \% \text {, o PSDB 30\%, o DEM } 27 \% \text {, o PPS } 5 \% \text { e o PTB } \\
3 \% \text {. Disponivel em: < http://www.clicrbs.com.br/diariocatarinense/jsp/default.jsp?uf=2\&local=18\&sect } \\
\text { ion=Pol\%EDtica\&newsID=a3181565.htm>. }\end{array}$ \\
\hline
\end{tabular}

08/03/11 Blumenau

Pelo acordo feito entre os quatro partidos, a divisão das gerências ficou assim distribuída: cinco para o PSDB, quatro para o PMDB e para o DEM, e uma para o PPS. Duas delas, consideradas essenciais, estão sendo ocupadas interinamente pelas ex-gerentes.

Disponível em: <http://www.clicrbs.com.br/jsc/sc/impressa/4,181,3232142,16644>.

10/03/11 Blumenau

O DEM e a Secretaria de Desenvolvimento Regional de Blumenau (SDR) ignoraram a investigação por suspeita de mau uso de carro público e mantiveram a indicação de engenheiro eletricista para a gerência de Infraestrutura da Secretaria de Desenvolvimento Regional de Blumenau.

Disponível em: <http://www.clicrbs.com.br/diariocatarinense/jsp/default.jsp?uf=2\&section $=$ Pol\%C3\% ADtica\&newsID =a3235387.htm>.

12/04/11 Jaraguá do Sul Confirmado pelo governador (DEM) para ficar no comando da Secretaria de Desenvolvimento Regional para a região de Jaraguá do Sul, o PSDB. Começa a composição dos 11 cargos que formam a estrutura da secretaria. Mas, para isso, ele vai ter de conversar com os partidos aliados do governo do Estado, principalmente PMDB, DEM, PPS, PTB e outros menores, que vão sugerir nomes para preencher os cargos. Disponível em: <http://www.clicrbs.com.br/anoticia/jsp/default2.jsp?uf=2\&local=18\&source $=\mathrm{a} 3271373 . \mathrm{xml} \&$ template $=4187$. dwt\&edition $=16876 \&$ section $=1192>$.

12/05/11 Joinville Além do secretário do PMDB, que já havia sido confirmado em fevereiro, 18 posições tiveram os nomes anunciados pelos partidos da base aliada do Governo. [...] A maior disputa entre as legendas era pela cadeira de diretor-geral, mas foi vencida pelo PSDB. Disponível em: < http://www.clicrbs.com.br/anoticia/ jsp/default.jsp? $\mathrm{uf}=2 \&$ local $=18 \&$ section $=$ Pol\%EDtica\&newsID $=$ a3308138.htm $>$.

20/05/11 Mafra Composição dos gerentes da 25a SDR de Mafra: Secretario Adjunto: PMDB - Itaiópolis

Consultor Jurídico - Rio Negrinho - PMDB

Assessor de Comunicação - (cargo não preenchido, disponível para o PSDB de São Bento)

Gerente de Administração e Finanças - PSD - Mafra

Gerente de Cultura, Turismo e Esporte - PSDB - Mafra

Gerente de Desenvolvimento Econômico Sustentável e Agricultura - PMDB - Campo Alegre

Gerente de Infraestrutura -PMDB - Papanduva

Gerente de Planejamento e Avaliação - PSDB - São Bento do Sul

Gerente de Saúde- DEM (PSD) - Rio Negrinho

Gerente de Educação - PMDB - São Bento do Sul

Gerente de Assistência Social, Trabalho e Habitação - DEM (PSD) - São Bento do Sul.

Disponível em: <http://www.portaldecanoinhas.com.br/noticias/8983>.

Quadro 3: Notícias das SDRs no ano 2011

Fonte: Elaborado pelos autores deste artigo (2011) 
Observa-se no Quadro 3 que as vinculações partidárias predominam no provimento dos cargos em comissão, confirmando, assim, o que Abrucio e Filippim (2008) e Birkner (2005) defendem: que as estruturas das SDRs são formadas por indivíduos que compõem a base governista.

\section{Procedimentos Metodológicos}

Esta seção descreve os procedimentos utilizados para a construção desta pesquisa e encontra-se organizada da seguinte forma: (i) enquadramento metodológico; e, (ii) procedimentos para coleta e tratamento de dados.

\subsection{Enquadramento Metodológico}

A pesquisa é de caráter descritivo, na forma de um estudo multicaso, com a abordagem quali-quantitativa, envolvendo a coleta de dados primários e secundários.

A natureza do objetivo consiste em uma pesquisa descritiva, visto que possibilita identificar de que forma são providos os cargos em comissão das SDRs. Segundo Richardson (1999), os estudos dessa natureza propõem-se a investigar e descobrir as características de um fenômeno.

A natureza do artigo envolve a estratégia multicaso, ou seja, de estudo de caso aplicado a mais de um objeto, aqui representado pelas 36 SDRs. O estudo multicaso proporciona uma maior abrangência dos resultados, não se limitando às informações de uma só SDR, possibilitando inferir uma proposição geral a cerca do tema. (RICHARDSON, 1999; LAKATOS; MARCONI, 2008)

A coleta dos dados contempla dados primários e secundários. Os dados primários são aqueles obtidos diretamente no campo (RICHARDSON, 1999), sendo extraídos de informações colhidas junto às SDRs e de registros no sítio do Tribunal Regional Eleitoral (TSE).
Os dados secundários são aqueles obtidos por meio de pesquisas bibliográficas realizadas sobre o tema.

A abordagem do problema de pesquisa é quali-quantitativa, visto que a partir da coleta de dados foram aplicados procedimentos de tabulação e técnicas estatísticas, além da análise e interpretação dos dados referentes ao provimento dos cargos comissionados, que permite compreender de que forma eles são providos. (RICHARDSON, 1999)

\subsection{Procedimentos para Coleta e Tratamento dos Dados}

O universo da pesquisa contempla a estrutura de cargos comissionados das áreas finalísticas de cada uma das 36 SDRs. O Quadro 4, a seguir, apresenta o tipo de Secretaria, a região em que está localizada, a quantidade de cargos voltados à atividade fim de cada SDR e a denominação dos cargos.

Constata-se, no Quadro 4, que a estrutura de cargos comissionados é similar em cada SDR, apenas ampliando-se novas denominações e/ou quantitativos nas SDRs de maior porte, resultando em 213 cargos comissionados que integram o foco da pesquisa. Destaca-se que a amostra é composta por 98 cargos, ou seja, $46 \%$ dos cargos das áreas finalísticas.

Para a identificação do nível de escolaridade dos ocupantes de cada cargo comissionado, inicialmente se fez necessária a proposição de perfil mínimo de escolaridade, já que a legislação que os instituiu não define esse requisito.

Os requisitos definidos envolvem a exigência de curso de nível superior em áreas afins à denominação $e$ às atribuições de cada cargo previstas na Lei Complementar n. 381/07 (SANTA CATARINA, 2007) e nos regimentos internos das SDRs.

$\mathrm{O}$ perfil de escolaridade proposto encontra-se descrito no Quadro 5. 


\begin{tabular}{|c|c|c|c|c|}
\hline TIPO & $\begin{array}{l}\text { DistribuiçÃo SDRs } \\
\text { (MICRORREGIÕES) }\end{array}$ & $\begin{array}{l}\text { NÚMERO DE CARGOS EM } \\
\text { COMISSÃo NAS ÁREAS FINA- } \\
\text { LÍSTICAS }\end{array}$ & $\begin{array}{c}\text { DENOMINAÇÃo dOS CARGOS COMISSIONADOS } \\
\text { NAS ÁREAS FINALÍSTICAS }\end{array}$ & $\begin{array}{l}\text { NÚMERO DE CARGOS } \\
\text { EM COMISSÃo NAS } \\
\text { ÁREAS FINALÍSTICAS - } \\
\text { AMOSTRA DA PESQUISA }\end{array}$ \\
\hline A & $\begin{array}{l}\text { Grande Florianópolis } \\
\text { e Joinville }\end{array}$ & 16 & $\begin{array}{l}\text { Gerente de Educação, Gerente de Assistência } \\
\text { Social, Trabalho e Habitação, Gerente } \\
\text { de Saúde, Gerente de Desenvolvimento } \\
\text { Econômico, Sustentável e Agricultura, } \\
\text { Gerente de Turismo, Cultura e Esporte, } \\
\text { Gerente de Projetos Especiais (2 } \\
\text { cargos) e Gerente de Infraestrutura. }\end{array}$ & 16 \\
\hline B & $\begin{array}{l}\text { Blumenau, Chapecó, } \\
\text { Criciúma, Itajaí, Lages. }\end{array}$ & 35 & $\begin{array}{l}\text { Gerente de Educação, Gerente de Assistência } \\
\text { Social, Trabalho e Habitação, Gerente } \\
\text { de Saúde, Gerente de Desenvolvimento } \\
\text { Econômico, Sustentável e Agricultura, Gerente } \\
\text { de Turismo, Cultura e Esporte, Gerente de } \\
\text { Projetos Especiais e Gerente de Infraestrutura. }\end{array}$ & 21 \\
\hline C & $\begin{array}{l}\text { Araranguá, Brusque, Caçador, } \\
\text { Campos Novos, Canoinhas, } \\
\text { Concórdia, Curitibanos, } \\
\text { Jaraguá do Sul, Joaçaba, } \\
\text { Laguna, Mafra, Rio do } \\
\text { Sul, São Miguel d'Oeste, } \\
\text { Tubarão, Videira e Xanxerê }\end{array}$ & 96 & $\begin{array}{l}\text { Gerente de Educação, Gerente de Assistência } \\
\text { Social, Trabalho e Habitação, Gerente } \\
\text { de Saúde, Gerente de Desenvolvimento } \\
\text { Econômico, Sustentável e Agricultura, } \\
\text { Gerente de Turismo, Cultura e Esporte } \\
\text { e Gerente de Infraestrutura. }\end{array}$ & 30 \\
\hline D & $\begin{array}{l}\text { Braço do Norte, Dionísio } \\
\text { Cerqueira, Ibirama, } \\
\text { Itapiranga, Ituporanga, } \\
\text { Maravilha, Palmitos, } \\
\text { Quilombo, São Joaquim, } \\
\text { São Lourenço do Oeste, } \\
\text { Seara, Taió e Timbó }\end{array}$ & 66 & $\begin{array}{l}\text { Gerente de Educação, Gerente de } \\
\text { Assistência Social, Trabalho e Habitação, } \\
\text { Gerente de Saúde, Gerente de } \\
\text { Desenvolvimento Econômico, Sustentável } \\
\text { e Agricultura, Gerente de Infraestrutura. }\end{array}$ & 31 \\
\hline Total & & 213 & & 98 \\
\hline
\end{tabular}

Quadro 4: Distribuição dos cargos comissionados das áreas finalísticas das SDRs

Fonte: Adaptado de Anexo VIII, Lei Complementar .n. 381/07 (SANTA CATARINA, 2007)

\section{GERÊNCIA/ÁREA}

Saúde

Projetos Especiais

Turismo, Cultura e Esporte

Infraestrutura

Desenvolvimento Econômico

Sustentável e Agricultura

Educação

Assistência Social, Trabalho e Habitação

\section{Perfil de Escolaridade Proposto}

Curso de nível superior voltados à saúde, assistência social e administração.

Qualquer curso de nível superior.

Curso de nível superior relacionado ao turismo, às artes, à educação

física, às relações internacionais e à administração.

Curso de nível superior em engenharia e/ou arquitetura.

Curso de nível superior relacionado à economia, engenharia, gestão ambiental, veterinária, zootecnia, agronomia e administração.

\section{Curso de nível superior afim a área de educação e administração}

Curso de nível superior relacionado ao serviço social, direito, psicologia, engenharia, arquitetura e administração.

Quadro 5: Escolaridade por área finalística

Fonte: Elaborado pelos autores deste artigo (2011) 
Na sequência, para iniciar a coleta de dados, foi construído um questionário contendo perguntas específicas sobre o nível de escolaridade do ocupante de cada cargo. Optou-se pelo envio do questionário por meio eletrônico para a Gerência de Recursos Humanos das 36 SDRs, das quais apenas 16 responderam, ou seja, $44 \%$ do total de SDRs.

A partir dos dados coletados, fez-se uma análise comparativa do perfil de escolaridade do ocupante de cada cargo com o perfil proposto no Quadro 4. Os resultados foram estruturados: (i) de forma global, considerando todos os cargos e todas as SDRs; (ii) de forma específica, por tipo de SDR (A, B, C, D); e, (iii) por cargo, considerando todas as SDRs.

Sobre a coleta de dados referente à filiação partidária dos ocupantes dos cargos comissionados, obteve-se inicialmente a relação dos ocupantes dos respectivos cargos junto à Secretaria de Administração do Estado de Santa Catarina, órgão responsável pelo processamento da folha de pagamento das SDRs, tendo-se como referência o mês de setembro de 2011.

Após, realizou-se o acesso ao sítio do Tribunal Regional Eleitoral do Estado de Santa Catarina, visando à identificação da filiação partidária dos ocupantes dos cargos comissionados de cada SDR. A pesquisa foi realizada no mês de outubro de 2011, sendo as informações consolidadas por SDR e de forma global.

No tratamento dos dados coletados de filiação partidária, visando a preservar a confidencialidade das informações, adotou-se os seguintes procedimentos de análise: (i) do total de cargos, ou seja, de forma global; (ii) os cargos por tipo de SDR (A, B, C e D); e, (iii) cada cargo finalístico considerando todas as SDRs.

Finalmente, foi possível confrontar as variáveis escolaridade e filiação partidária dos ocupantes dos cargos comissionados de forma a demonstrar sua efetiva relação. Para tal, utilizou-se dos seguintes procedimentos: (i) verificou-se a filiação partidária dos ocupantes de cargos que possuem ou não nível superior; $e$, (ii) verificou-se a filiação partidária dos ocupantes de cargos, cujos cursos foram considerados compatíveis ou não com o perfil de escolaridade proposto.

Com a aplicação dos procedimentos de coleta $e$ tratamento de dados, previstos nesta seção, apresenta-se, na seção 4, os resultados obtidos.

\section{Resultados}

Nesta seção, apresentam-se os resultados da pesquisa organizados da seguinte forma: (i) perfil de escolaridade dos ocupantes de cargos comissionados (gerentes) das SDRs; (ii) comparativo entre o perfil de escolaridade dos gerentes com o perfil proposto; (iii) filiação partidária dos gerentes; $e$, (iv) relação entre as variáveis escolaridade e filiação partidária dos ocupantes dos cargos gerenciais.

\subsection{Perfil de Escolaridade do Gerentes da Áreas Finalísticas da SDRs}

A análise do perfil de escolaridade dos ocupantes dos cargos gerenciais levou em consideração os níveis de escolaridade: ensino fundamental, ensino médio, ensino superior e pós-graduação. O Gráfico 1 apresenta, na forma percentual, os níveis de escolaridade dos ocupantes dos cargos gerenciais:

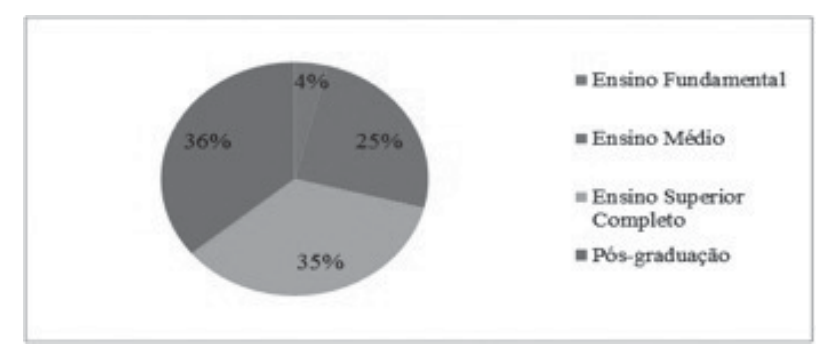

Gráfico 1: Escolaridade dos gerentes das áreas finalísticas Fonte: Elaborado pelos autores deste artigo (2011)

Os resultados demonstram que $71 \%$ (35\% ensino superior e $36 \%$ pós-graduados) da população pesquisada possui curso superior, sendo que o restante é dividido entre a escolaridade de ensino médio (25\%) e ensino fundamental (4\%).

Cabe frisar que os cargos em tela são do tipo DGS ou FTG que exigem preferencialmente para sua ocupação escolaridade de nível superior em curso de graduação (SANTA CATARINA, 2007), assim o percentual de $29 \%$ sem escolaridade superior é representativa, podendo comprometer a formulação e execução das políticas públicas no âmbito regional,

A seguir, no Gráfico 2, apresentam-se os resultados do nível de escolaridade levando-se em consideração cada cargo. 


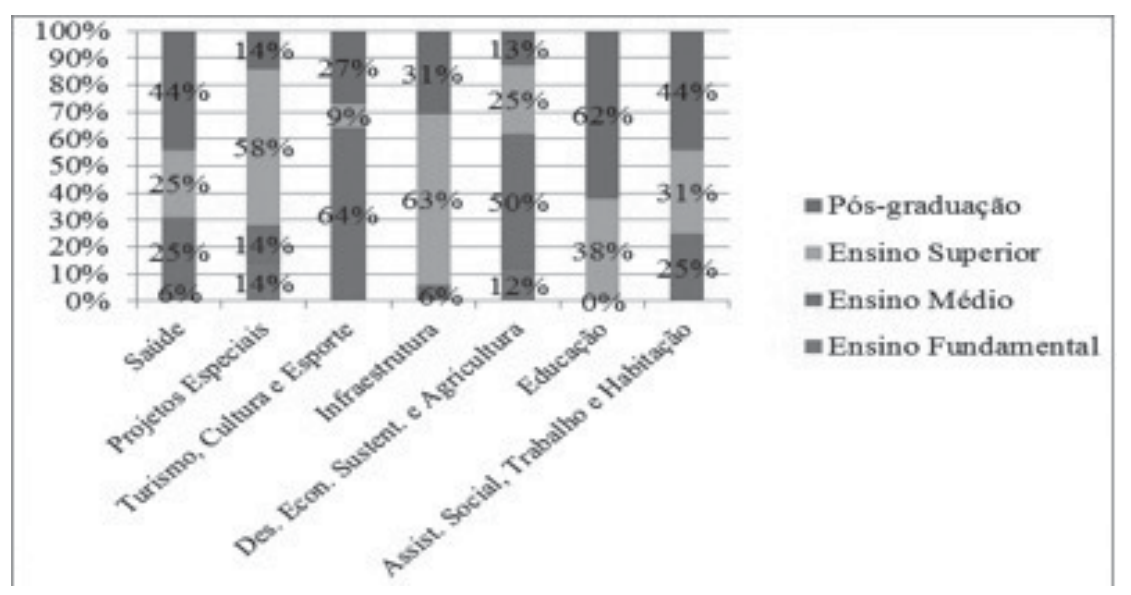

Gráfico 2: Escolaridade por gerência finalística

Fonte: Elaborado pelos autores deste artigo (2011)

Constata-se que o cargo Gerente de Educação é o que detém o maior percentual de ocupantes com nível superior, chegando a $100 \%$, sendo que $62 \%$ possuem pós-graduação. O cargo de Gerente de Infraestrutura é o segundo neste quesito, obtendo $94 \%$ com nível superior e $31 \%$ com pós-graduação.

Os cargos de Gerente de Assistência Social, Trabalho e Habitação e Gerente de Saúde se assemelham possuindo $75 \%$ e $69 \%$, respectivamente, de profissionais com nível superior. Destes, $31 \%$ e $25 \%$, respectivamente, possuem pós-graduação. No que se refere ao ensino médio, as duas áreas apresentam o mesmo percentual (25\%), sendo que a da Saúde detém $6 \%$ dos ocupantes com ensino fundamental.
O cargo de Gerente de Projetos Especiais registrou $72 \%$ de ocupantes com nível superior, sendo $14 \%$ pós-graduados, $14 \%$ com ensino médio e outros $14 \%$ com ensino fundamental.

Os cargos de Gerente de Turismo, Cultura e Esporte e Gerente de Desenvolvimento Sustentável e Agricultura foram aqueles que demonstraram uma maior deficiência no quesito escolaridade. No primeiro, apenas $36 \%$ possuem ensino superior, sendo $27 \%$ com pós-graduação e $64 \%$ com apenas ensino médio. No segundo, $38 \%$ detêm nível superior, sendo $13 \%$ pós-graduados, $50 \%$ com ensino médio e $12 \%$ com apenas ensino fundamental.

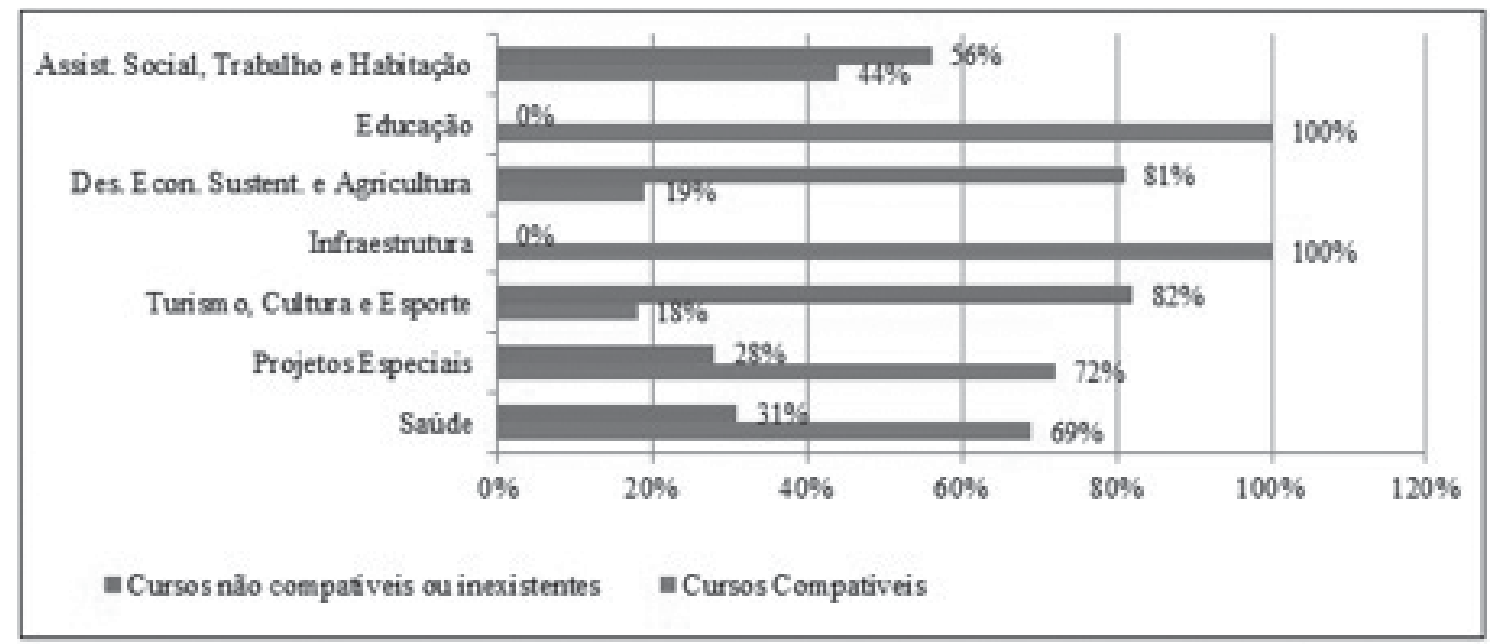

Gráfico 3: Comparativo entre a escolaridade proposta e a dos gerentes das áreas finalísticas

Fonte: Elaborado pelos autores deste artigo (2011) 


\subsection{Análise Comparativa entre o Perfil de Escolaridade dos Gerentes das Áreas Finalísticas das SDRs com o Perfil Proposto}

A partir da construção do perfil de escolaridade para os cargos das áreas finalísticas das SDRs, demonstrado no Quadro 5 da Seção 3.2, realizou-se um comparativo dessa proposta com o perfil atual dos ocupantes de tais cargos, conforme demonstrado no Gráfico 3.

Os resultados revelam que existe compatibilidade entre a escolaridade proposta (tipo de curso) em relação à escolaridade dos gerentes para os cargos de Gerente de Educação (100\%) e Gerente de Infraestrutura (100\%). Já para os cargos de Gerente de Projetos Especiais e Gerente de Saúde o nível de compatibilidade diminui para $72 \%$ e $69 \%$, respectivamente. $\mathrm{Na}$ área de Assistência Social, Trabalho e Habitação a compatibilidade é de $44 \%$. Destacam-se negativamente os cargos de Turismo, Cultura e Esporte e Gerente de Desenvolvimento Econômico Sustentável e Agricultura, apresentando baixos percentuais de compatibilidade entre as variáveis confrontadas (18\% e 19\%).

Em termos gerais e utilizando o montante de 98 cargos pesquisados, 39 deles não atendem o requisito de escolaridade proposto, o que equivale a $40 \%$ do total.

\subsection{Filiação Partidária dos Gerentes das Áreas Finalísticas das SDRs}

De posse da lista dos ocupantes dos cargos em comissão das áreas finalísticas das SDRs, efetuou-se uma pesquisa nominal no sítio < http://filiaweb.tse. gov.br/filiaweb > para verificar se os ocupantes dos cargos objeto de estudo possuem filiação partidária com os partidos que compõem a base do governo estadual (DEM, PMDB, PSDB, PPS, PSC, PTB, PTC, PSL e PRT).

Ressalte-se que foram analisados 98 ocupantes de cargos comissionados que perfazem a amostra do presente estudo. Os resultados constam do Gráfico 4:

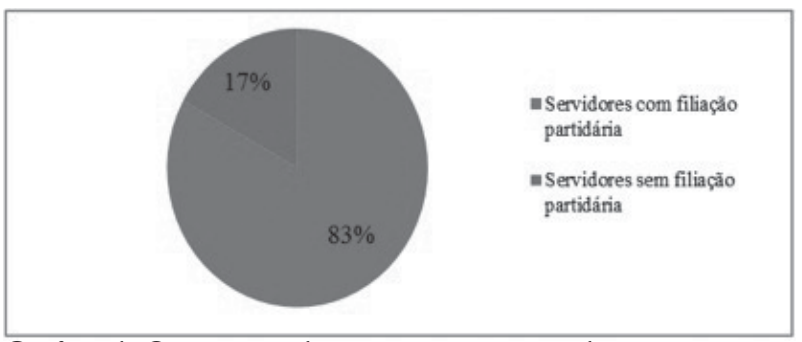

Gráfico 4: Ocupantes de cargos comissionados versus filiação partidária

Fonte: Elaborado pelos autores deste artigo (2011)

Percebe-se que $83 \%$ dos ocupantes de cargos comissionados possuem filiação partidária com os partidos que formam a base governamental. Esse índice confirma que as nomeações para cargos em comissão no âmbito da administração pública tem forte componente político-partidário como um dos critérios para sua ocupação.

Utilizando outros métodos de pesquisa (entrevista), Abrucio e Filippim (2008) ao analisar as SDRs, corroboram a intensa influência da base governamental na escolha dos gerentes que ocupam os cargos da estrutura das SDRs.

Analisa-se também a filiação partidária, de acordo com o tipo de SDRs ("A", "B", "C" e "D"), considerando que das 16 SDRs analisadas, duas são do tipo "A" (100\% do total), três são do tipo "B" $(60 \%$ do total), cinco são do tipo "C" ( $31 \%$ do total) e seis são do tipo " $D$ " ( $46 \%$ do total).

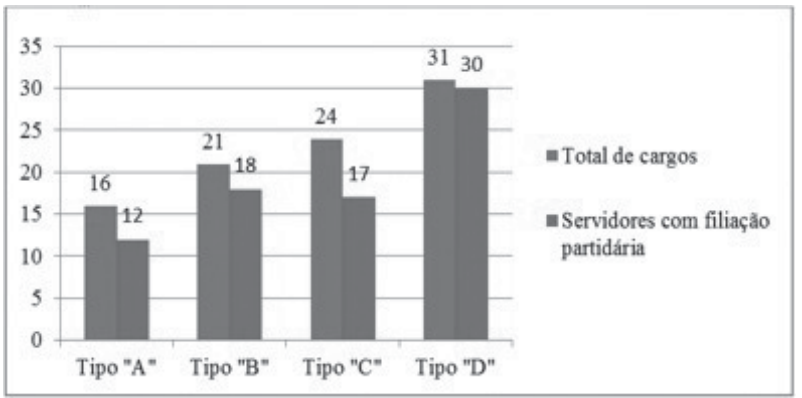

Gráfico 5: Filiação partidária por tipo de SDR

Fonte: Elaborado pelos autores deste artigo (2011)

As SDRs do tipo "A" apresentam $75 \%$ de cargos comissionados ocupados por servidores que possuem filiação partidária. As do tipo "B" possuem $85 \%$, as do tipo "C" $71 \%$ e por último, as do tipo "D" possuem 97\% de servidores que possuem filiação partidária nos cargos pesquisados. Os resultados representam que quanto menor a estrutura (porte) da SDR, maior 
a influência político-partidária no provimento dos cargos comissionados. Por envolverem regiões geográficas e cidades sedes menores, o conflito e a disputa política-partidária se torna mais intensa, resultando na nomeação de profissionais com participação ativa $e$ vivência na política local. Assim, evidencia-se que na menor estrutura de cargos comissionados (SDRs porte "D"), ser filiado aos partidos da base do governo atual é quase uma das condições para assumir cargo comissionado nas áreas finalísticas dos respectivos órgãos.

Outro ponto a ser analisado nesta seção é a filiação partidária por tipo de cargo comissionado, de acordo com as áreas finalísticas investigadas.

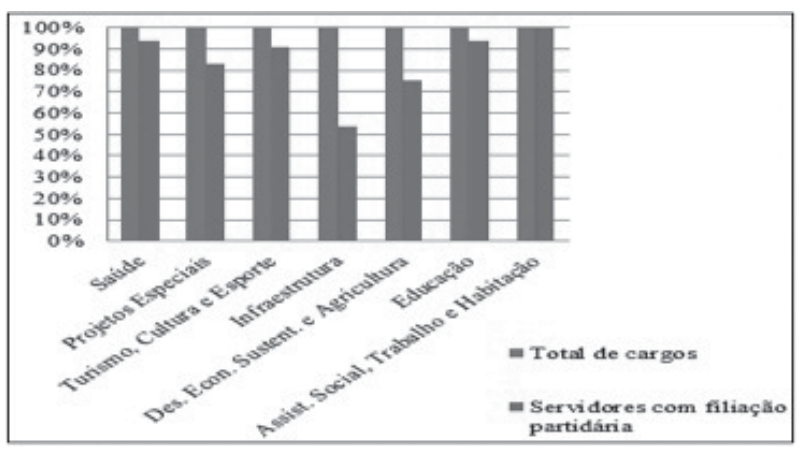

Gráfico 6: Filiação partidária dos gerentes das áreas finalísticas

Fonte: Elaborado pelos autores deste artigo (2011)

Os resultados revelam que: (i) os cargos de Gerente de Assistência Social, Trabalho e Habitação Social (100\%), Gerente de Saúde (94\%), Gerente de Educação (94\%) e Gerente de Turismo, Cultura e Esporte (91\%) são as que detêm o maior número de ocupantes de cargos com filiação partidária; (ii) os cargos de Gerente de Projetos Especiais (83\%) e Gerente de Desenvolvimento Econômico, Sustentável e Agricultura $(75 \%)$ demonstraram resultados próximos à média geral que será apresentada no Gráfico 7; e, (iii) o cargo de Gerente de Infraestrutura (54\%) obteve o resultado mais baixo na relação filiação partidária / tipo de cargo ocupado, indicando que o critério político não é evidenciado tão fortemente para a sua ocupação. Tal percentual pode ser explicado pela exigência legal prevista no artigo 168 da Lei Complementar n. 381/07 (SANTA CATARINA, 2007) na qual fica claro que o ocupante do cargo precisa estar inscrito no Conselho Regional de Engenharia, Arquitetura e Agronomia (CREA).

\subsection{Relações entre as Variáveis Escolaridade e Filiação Partidária no Provimento dos Cargos Comissionados das Áreas Finalísticas das SDRs}

A partir dos dados relativos ao nível de escolaridade, dos ocupantes dos cargos comissionados, apresentado no Gráfico 1, analisa-se a relação com a filiação partidária. No Gráfico 7, a seguir, o nível de escolaridade é desmembrado em dois grupos: sem curso de nível superior e com curso de nível superior.

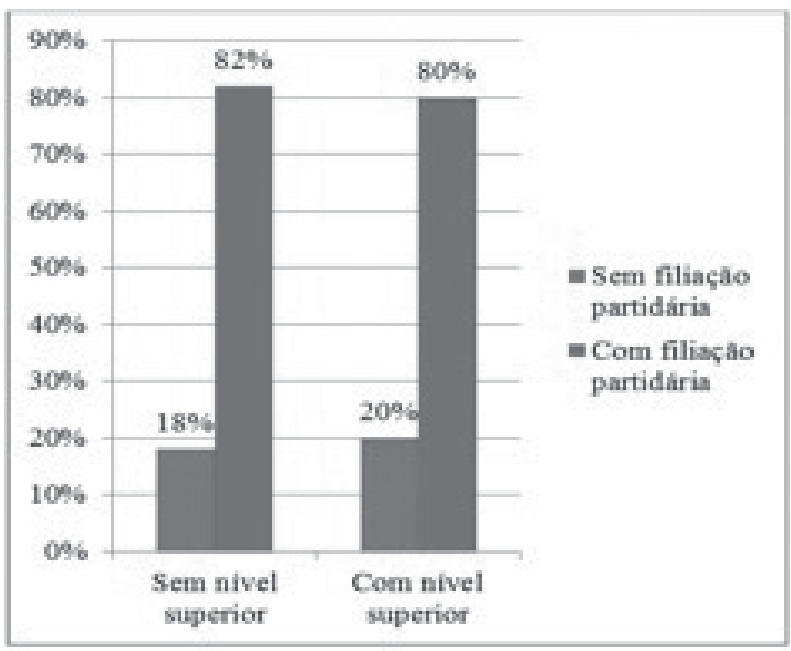

Gráfico 7: Escolaridade versus filiação partidária Fonte: Elaborado pelos autores deste artigo (2011)

Os resultados indicam números semelhantes na relação da escolaridade com a filiação partidária. Dos ocupantes de cargos comissionados, $20 \%$ dos que possuem nível superior não são filiados a partidos políticos e $18 \%$ dos que não possuem nível superior também não são filiados. Isso indica que não há uma relação inversa entre escolaridade e indicação política partidária para a ocupação dos cargos finalísticos nas SDRs, ou seja, com ou sem curso superior, a variável filiação partidária é utilizada indistintamente para o provimento de cargos comissionados.

No Gráfico 8 apresenta-se o percentual dos gerentes que possuem escolaridade compatível com a exigida para o cargo (Gráfico 3) em relação à filiação partidária (Gráfico 6). 


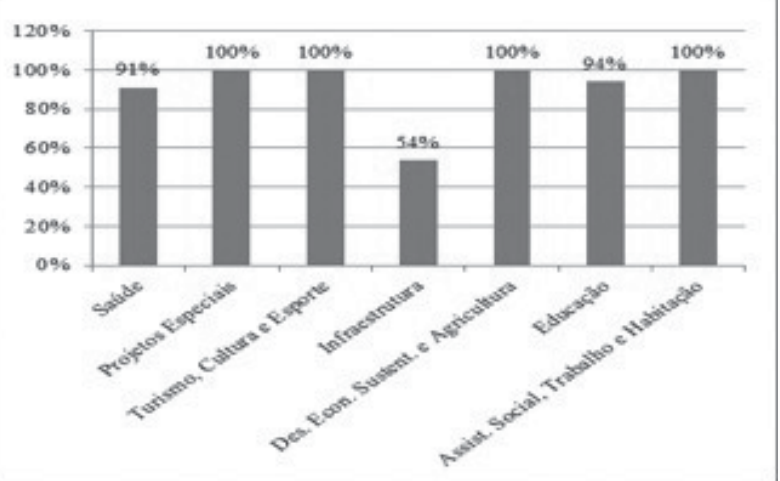

Gráfico 8: Cursos compatíveis versus filiação partidária Fonte: Elaborado pelos autores deste artigo (2011)

Observa-se no Gráfico 8 que 100\% dos gerentes das áreas de projetos especiais; turismo, cultura $e$ esporte; desenvolvimento econômico sustentável e agricultura; assistência social, trabalho e habitação possuem filiação político-partidária. Já para a área de educação o percentual é de $94 \%$, para a área da saúde $91 \%$ e de infraestrutura é de $54 \%$.

No Gráfico 9 apresenta-se o percentual dos ocupantes de cargos de nível gerencial que não possuem escolaridade compatível (Gráfico 3) para o exercício do cargo em relação à filiação político-partidária (Gráfico 6).

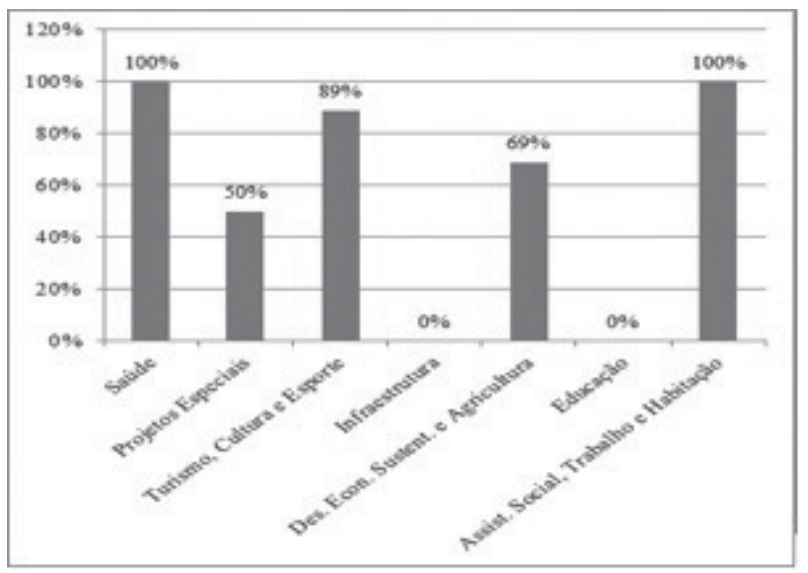

Gráfico 9: Cursos não compatíveis versus filiação partidária Fonte: Elaborado pelos autores deste artigo (2011)

Constata-se no Gráfico 9 que $100 \%$ dos gerentes das áreas de saúde e assistência social, trabalho $e$ habitação, que não possuem escolaridade alinhada com o cargo, possuem filiação político-partidária. Para os gerentes da área de turismo, cultura e esporte a filiação político-partidária é de $89 \%$; em desenvolvimento econômico, sustentável e agricultura são de $69 \%$; projetos especiais, $50 \%$. Para as áreas de infraestrutura e educação a não ocorrência da filiação político-partidária decorre de que $100 \%$ dos gerentes possuem a escolaridade compatível com a exigida pelo cargo, já analisada no Gráfico 8.

Considerando os resultados apresentados no Gráfico 8 em relação ao Gráfico 9, constata-se que não existe predominância de filiação político-partidária para os gerentes que possuem escolaridade compatível com o cargo em relação aos gerentes que não possuem escolaridade compatível. Observa-se que nas áreas de projetos especiais; turismo, cultura e esporte e desenvolvimento econômico, sustentável e agricultura, cujos ocupantes possuem escolaridade compatível, a incidência de filiação político-partidária é superior aos ocupantes que não possuem formação compatível. Já para a área de saúde o percentual de filiação político-partidária dos gerentes que não possuem formação compatível com a escolaridade exigida é superior aos que possuem. A área de assistência social, trabalho $e$ habitação possui o mesmo percentual de filiação.

Dessa forma, a análise das variáveis do nível de escolaridade e filiação político-partidária na ocupação dos cargos comissionados das áreas finalísticas das SDRs, apresentadas nesta seção, evidenciam que: (i) $29 \%$ dos gerentes das áreas finalísticas das SDRs não possuem curso de nível superior; (ii) os cargos de Gerente de Turismo, Cultura e Esporte e Gerente de Desenvolvimento Econômico Sustentável e Agricultura foram os que demonstraram uma maior deficiência no quesito escolaridade, $36 \%$ e $38 \%$ respectivamente possuem curso de nível superior; (iii) $40 \%$ dos gerentes não possuem escolaridade compatível com as funções que desempenham, considerando o perfil de escolaridade proposto; (iv) 83\% dos gerentes das áreas finalísticas são filiados a partidos políticos da base do governo; (v) nos cargos de Gerente de Assistência Social, Trabalho e Habitação Social (100\%), Gerente de Saúde (94\%), Gerente de Educação (94\%) e Gerente de Turismo, Cultura e Esporte (91\%) são os que detêm o maior número de ocupantes de cargos com filiação partidária; (vi) o cargo de Gerente de Infraestrutura obteve o menor percentual de ocupantes com filiação partidária (50\%); e, (vii) inexiste predominância de filiação político-partidária dos gerentes que possuem 
nível de escolaridade compatível com o cargo em relação àqueles que não possuem.

Verificou-se ainda que o nível de escolaridade definido pela Lei Complementar n. 381/07 (SANTA CATARINA, 2007) é observado nas nomeações, até porque se utiliza a expressão "preferencialmente com curso de graduação", requisito genérico que abre um leque de possibilidades para a autoridade com poder de nomear. No entanto, a compatibilidade entre o perfil de escolaridade do cargo versus o perfil do ocupante, normalmente requerido em processos de recrutamento e seleção na área privada, não é verificada em boa parte das nomeações (40\%). Isso pode ser explicado pelo número acentuado de indicações político-partidárias, muito presente nas coligações formadas por diversos partidos, e pela não exigência obrigatória de formação superior em nível de graduação.

Destaca-se que a variável escolaridade é apenas um dos requisitos que devem ser observados no estabelecimento de um perfil profissional para a ocupação de vaga na iniciativa privada, conforme observa Lacombe e Heilborn (2003). Portanto, a partir dessa premissa para os cargos comissionados das SDRs, em análise, o percentual de $60 \%$ de gerentes com escolaridade compatível com o perfil proposto poderia diminuir consideravelmente, na medida em que se definir um perfil mais abrangente para os cargos comissionados.

Considerando os resultados apresentados desta pesquisa e o modus operandi das nomeações de cargos em comissão na administração pública, retratado principalmente por Ayllon e Guerreiro (2005) e Santos (2009) e, no caso catarinense, por Abrucio e Filippim (2008), pode-se afirmar que o processo de escolha dos ocupantes de cargos comissionados é diretamente influenciado pela filiação partidária dos indicados, a partir dos partidos políticos que compõem a base de sustentação do governo.

\section{Considerações Finais}

O estabelecimento de parâmetros qualitativos e transparentes para a escolha dos ocupantes de cargos comissionados, assim como acontece com os cargos de provimento efetivo, é necessário para a melhoria da gestão pública, como também serve para limitar as nomeações de caráter essencialmente político.
O debate sobre este tema enseja uma questão emergente, na qual os governos precisam estar preparados para dar respostas rápidas e com qualidade para as grandes demandas da sociedade. Isso exige que os governos tenham profissionais preparados e capacitados para tais desafios no âmbito da gestão pública.

Os resultados do estudo apontam que a variável filiação partidária tem influência direta na ocupação dos cargos comissionados das áreas finalísticas das SDRs, visto que $83 \%$ dos gerentes das áreas finalísticas possuem filiação partidária. Também em relação ao nível de escolaridade, $29 \%$ dos gerentes das SDRs não possuem curso de nível superior e $40 \%$ dos gerentes não possuem nível de escolaridade compatível com o exigido para o exercício do cargo.

Diante dos resultados da pesquisa, conclui-se que o objetivo geral foi plenamente atendido, quando se identificou a influência do nível de escolaridade e da filiação partidária para o exercício de cargos comissionados no âmbito das SDRs.

As contribuições da pesquisa para a gestão pública e, consequentemente, para a área de administração ficam evidenciadas: (i) na ampliação do referencial teórico sobre o tema, contribuindo para novas pesquisas e estudos sobre a dinâmica de provimento de cargos nas estruturas de governo; (ii) no subsídio aos dirigentes públicos, para a melhoria das práticas de gestão, em especial na ampliação dos critérios de indicação e seleção de candidatos para os cargos públicos; (iii) na tomada de decisão governamental, no sentido de criar um referencial legal específico que discipline o perfil dos cargos comissionados para fins de provimento.

Como limitações do estudo destacam-se: (i) a coleta de dados contemplou $44 \%$ das SDRs, devido ao não envio do questionário por parte de 20 SDRs; e, (ii) dados desatualizados no sistema corporativo de recursos humanos do Estado referente ao nível de escolaridade e respectivos cursos realizados pelos ocupantes dos cargos.

Como recomendações para trabalhos futuros destacam-se: (i) ampliar e estender a pesquisa para todos os cargos das SDRs, em especial os que envolvem atividades meio; e, (ii) aplicar a pesquisa junto aos cargos comissionados da Secretarias Centrais e aos órgãos da administração indireta do Estado de Santa Catarina. 


\section{REFERÊNCIAS}

ALENCAR, R. A. A carreira de gestor público e sua formação. 2006. 168f. Dissertação (Mestrado em Saúde Coletiva) - Universidade Federal do Rio de Janeiro, Rio de Janeiro, 2006. Disponível em: < http://objdig.ufrj.br/96/ teses/RicardoArraesdeAlencar.pdf $>$. Acesso em: 24 abr. 2012.

AYLLÓN, B.; GUERRERO, V. G. Brasil, dos años de gobierno Lula. Política Exterior, v. 103, enero-feb. 2005.

BERNARDI, M. M. E.; CAMPOS, E. S. A. A função estratégica dos cargos em comissão: a experiência de Minas Gerais com os Especialistas em Políticas Públicas e Gestão Governamental (EPPGGs) e os Empreendedores Públicos. In: EnAPG, 4, 2010, Vitória/ES. Anais... Vitória: 2010. CD-ROM

\section{BRASIL. Constituição da República Federativa do}

Brasil de 1988. Disponível em: <http://www.planalto. gov.br/ccivil_03/constituicao/constitui\%C3\%A7ao.html>. Acesso em: 15 jun. 2011.

CÂMARA, L. M. O cargo público de livre provimento na organização da administração pública federal brasileira: uma introdução ao estudo da organização da direção pública na perspectiva de estudos organizacionais.

Revista de Administração Pública, [online], v. 43, n. 3, p. 635-659, 2009.

CÔRREA, V. L. de A. Perfil de los Ocupantes de Cargos de Confianza del Ejecutivo Federal Brasileño: una comparación entre el gobierno de FHC y Lula (1996 a 2006). Encontro Nacional de Pós-graduação em Administração e Pesquisa. Rio de Janeiro, 2010.

DUTRA, A. et al. Sistema de Avaliação de Desempenho das Secretarias de Desenvolvimento Regional do Governo do Estado de Santa Catarina: Resultados Preliminares da Aplicação de um Modelo Construtivista. II Encontro de Administração Pública e Governança da ANPAD. Salvador, 2008.

FILIPPIM, E. S.; ABRUCIO, F. L. Quando Descentralizar é Concentrar Poder: a experiência de Santa Catarina. In: XXXII Encontro da ANPAD. Rio de Janeiro, 2008.

Anais... Rio de Janeiro, 2008.

\section{LAKATOS, E. M.; MARCONI, M. A. Metodologia}

Científica. 5. ed. 2. Reimp. São Paulo: Atlas, 2008.

LONGO, F. A consolidação institucional do dirigente público. Revista do Serviço Público, [online], n. 2, p. 05-32, 2003.

OLIVIERI, C. Política, burocracia e redes sociais: as nomeações para o alto escalão do Banco central do Brasil. Revista de Sociologia e Política. Curitiba, n. 29, p. 147-168, nov. 2007.

\section{RICHARDSON, R. J. Pesquisa Social - Métodos e}

Técnicas. 3. ed. São Paulo: Atlas, 1999.

SANTA CATARINA. Lei Complementar n. 243, de 30 de janeiro de 2003. Estabelece nova Estrutura Administrativa do Poder Executivo. Disponível em: $<$ http://www.sea.sc.gov.br/index.php?option =com docman\&task $=$ cat_view\&gid $=40 \&$ Itemid $=64 \&$ lang $=$ bra zilian_portuguese $\geq$. Acesso em: 22 jun. 2011.

Lei Complementar n. 285, de 30 de janeiro de 2003. Transforma cargos no âmbito do Poder Executivo Estadual $e$ adota outras providências. Disponível em: $<$ http://www.pge.sc.gov.br/index.php?option=com wrapper\&Itemid $=163>$. Acesso em: 23 abr. 2012.

. Lei Complementar n. 381, de 7 de maio de 2007. Dispõe sobre o modelo de gestão e a estrutura organizacional da Administração Pública Estadual. Disponível em: < http://www.sea.sc.gov.br/index.php? option $=$ com_docman\&task $=$ cat_view\&gid $=40 \&$ Itemid $=6$ 4\&lang=brazilian_portuguese $\geq$. Acesso em: 22 jun. 2011.

Lei Complementar n. 534, de 30 de janeiro de 2003. Altera dispositivos da Lei Complementar $n$. 381 , de 2007, que dispõe sobre o modelo de gestão e a estrutura organizacional da administração pública estadual e estabelece outras providências. Disponível em: <http://www.pge.sc.gov.br/index.php?option=com wrapper\&Itemid $=163>$. Acesso em: 22 jun. 2011.

Decreto n. 1.836, de 6 de novembro de 2008. Veda a nomeação de cônjuge, companheiro(a) ou parente, para cargo em comissão, de confiança ou de função gratificada na administração publica estadual direta $e$ indireta e estabelece outras providencias. Disponível em: <http://www.pge.sc.gov.br/index.php?option=com wrapper\&Itemid=163>. Acesso em: 16 out. 2011. 
Decreto n. 2.640, de 22 de setembro de 2009 .

Aprova o regimento interno das Secretarias de Estado de Desenvolvimento Regional da grande Florianópolis e de Joinville e a distribuição dos cargos de provimento em comissão que compõem sua estrutura, e estabelece outras providencias que dispõe sobre o modelo de gestão e a estrutura organizacional da administração pública estadual e estabelece outras providências. Disponível em: <http://www.pge.sc.gov.br/index.php?option=com wrapper\&Itemid=163>. Acesso em: 12 out. 2011.

Lei n. 15.381, de 17 de dezembro de 2010 . Disciplina a nomeação para cargos em comissão no âmbito dos órgãos dos Poderes Executivo, Legislativo, Judiciário e do Tribunal de Contas do Estado e adota outras providencias. (Lei da Ficha Limpa). Disponível em: <http://www.pge.sc.gov.br/index.php?option =com wrapper\&Itemid=163>. Acesso em: 17 out. 2011.

SANTOS, L. C. dos. Burocracia profissional e a livre nomeação para cargos de confiança no Brasil e nos EUA.

Revista do Serviço Público. Brasília 60 (I): 05-28, jan./ mar., 2009.

SEGUNDO, A. N. R. L. Parâmetros para o controle jurisdicional do provimento dos cargos em comissão. Dissertação de Mestrado, UFCE, Fortaleza, 2010.

WIARDA, H. J. O Modelo Corporativo na América Latina e a Latino-americanização dos Estados

Unidos. Petrópolis: Vozes, 1983.

WOLKMER, A. C. Repensando a questão da historicidade do Estado e do Direito na América Latina. Panóptica, Vitória, ano 1, n. 4, dez., p. 82-95, 2006. Disponível em: <http://www.panoptica.org/dezembro2006pdf/ 7RepensandoaquestaodahistoricidadedoEstadoedo DireitonaAmricaLatina.pdf> . Acesso em: 24 abr. 2012. 